\title{
Voltage \& Current Magnitude Pattern Recognization by Using Fuzzy Logic Toolbox for Fault Types Classification
}

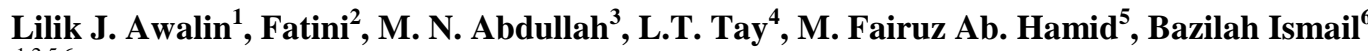 \\ ${ }^{1,2,5,6}$ Universiti Kuala Lumpur, British Malaysian Institute Jalan Sungai Batu 8 Gombak, Selangor, Malaysia \\ ${ }^{3}$ Green and Sustainable Energy (GSEnergy) Focus Group, Faculty of Electrical and Electronic Engineering, \\ Universiti Tun Hussein Onn Malaysia, 86400 Parit Raja, Batu Pahat, Johor, Malaysia \\ ${ }^{4}$ School of Electical and Electronic Enigneering, Universiti Sains Malaysia, Engieering Campus, 14300, \\ Nibong Tebal, Penang, Malaysia
}

\section{Article Info}

Article history:

Received Apr, 2018

Revised Jun 21, 2018

Accepted Jul 5, 2018

\section{Keywords:}

Distribution network

Fault resistance

Fault type classification

Fuzzy logic

Single line to ground fault

\begin{abstract}
This research introduces the appropriate input pattern of Fuzzy Logic design for fault type classification of Single Line to Ground Fault at distribution network. The proposed design is solely using Fuzzy Logic as the research technique with input data from PSCAD simulation. PSCAD software simulate the circuit configuration for fault disturbance at the distribution network. The research technique was applied with multiples input values of voltage and current that extracted from the PSCAD simulation. This research testifies the output result by using different fault resistance values; $0.01 \Omega$, $10 \Omega, 30 \Omega, 50 \Omega$ and $70 \Omega$. Voltage sag and current swell of phase a, b and c that were obtained from the PSCAD simulation have been used as the input variables for Fuzzy Logic design. The acquired results that represented in average accuracy shown that voltage sag and current swell can draw a satisfying accuracy in classifying the fault type.
\end{abstract}

Copyright $@ 2018$ Institute of Advanced Engineering and Science. All rights reserved.

\section{Corresponding Author:}

Lilik J. Awalin,

Universiti Kuala Lumpur, British Malaysian Institute,

Jalan Sungai Batu 8 Gombak, Selangor, Malaysia.

Email: lilik@unikl.edu.my

\section{INTRODUCTION}

In recent years, electrical power system has been used in generation, transmission, distribution and also for load systems. The need of electrical power system in daily basis, of course, to provide the electricity for each work globally which includes the medication, construction, and schools [1]. However, when fault at distribution network occurs, it will reduce the reliability and continuity of power delivery. Faults, as been mentioned by [2]-[5] are the most undesirable condition in an electrical power system for which involving the severe effect not only towards the system, but also affect the daily basis, human and environment itself. So, it is important to maintain the reliability and continuity of power delivery.

In case of permanent fault occurs in transmission or distribution network, the protection devices are not able to work since the fault is unable to make clearance by itself [6]-[8]. Hence, fault is in need to be detected instantly to prevent the problem to happen. In determining the fault location, one of the most essential thing is fault type classification [9]-[13].

On the other hand, many methods to identify the fault types have been introduced by the researchers in [3], [9]-[14] which are Artificial Neural Network, Wavelet transform, and Fuzzy Logic. Artificial Neural Network is widely used for its programming technique to solve the non-linear issues and also the problem with fault detection and type classification in electrical power system [9]. It is equipped with distinctiveness of parallel processing, non-linear mapping, associative memory, and also with the learning abilities either online or offline [3]. Along with that, ANN has the great features of making it too be considerably used for 
fault type classification which are able to tolerate with the dynamic changes in electrical power systems and gives the most accurate and quickest outcome [3]. Conquering all the advantages, ANN however is still lacking in several issues. The issues may be coming from the selection of network type, criteria for termination, the network architecture (involves the number of layers' selection, activation functions selection, and algorithm parameters learning) [13]. For this method, it covers for transmission network only, no further research has been done to use ANN for fault type classification at distribution network.

Another method of classifying fault types is wavelet transform. From [3], wavelet transform is able to select and analyse the data from transient signals not only in frequency domain, but also in time domain, both in simultaneously. It can analyse the data for different type of fault conditions with different transient voltage travelling waves. Besides, [13] mentioned that with the function of filtering, it is reliable enough to filter and remove electrical noise. The tool which is commonly used for this method is Multi-Resolution Analysis (MRA) that decomposes the original signal into a lower frequency signals (known as approximations) and higher frequency signals (known as details) [11]. Moreover, wavelet energy is considerably able to be a measure of normal signals and faulty signals, in order to classify the faulty groups and normal groups [13]. This method is usually combined with other method such as Neural Network and Fuzzy Logic. The rate of accuracy for Wavelet Transform with combination of other methods may exceed 95\% of accuracy, which can be said that it is reliable to be used as a method of fault type classification. However, researches shows that this kind of method can be used for LG fault only, and further research can be extended to identify other type of faults [11]. Above all, all of the methods focusing on the transmission network and only few researches has been done to identify the type of fault at distribution network. Hence, this research shows its interest in Fuzzy Logic, introduced by Dr. Lotfi Zadeh from University of California back in 1960s. According to [15], Fuzzy Logic is one of the approach to compute the computer language based on different degrees of truth besides the only "truth or false" by Boolean logic. Most commonly, Fuzzy Logic is used for control systems such as car control system, aerospace vehicle control systems, and kitchen appliances [16]. The reason for which the research is using Fuzzy Logic is that, it is easy to be understand for its language and system, and also provide the most precise results [12]. Fuzzy Logic can give a precise and smoother result as it is using range in between 'true or false' to provide multiple results for each different range.

Hence, Fuzzy Logic is one of the suitable methods to classify the type of faults for this research [12]. So, due to the above reasons, Fuzzy Logic is used in this work. The aim of this research is to create a better system to classifying the type of fault by using the ability of Fuzzy Logic. This research aims to observe the behavior of the software in order to get the results; whether or not the system can be carried out by using Fuzzy Logic.

\section{SIMULATION}

The circuit constructed with 18 nodes for the data reference. Each of the nodes represent a point where the fault occurrence takes place. Each of the nodes has different distance from each other in order to determine the effect of fault location to the simulation results. A simplified circuit configuration for fault analysis is as shown in Figure 1.

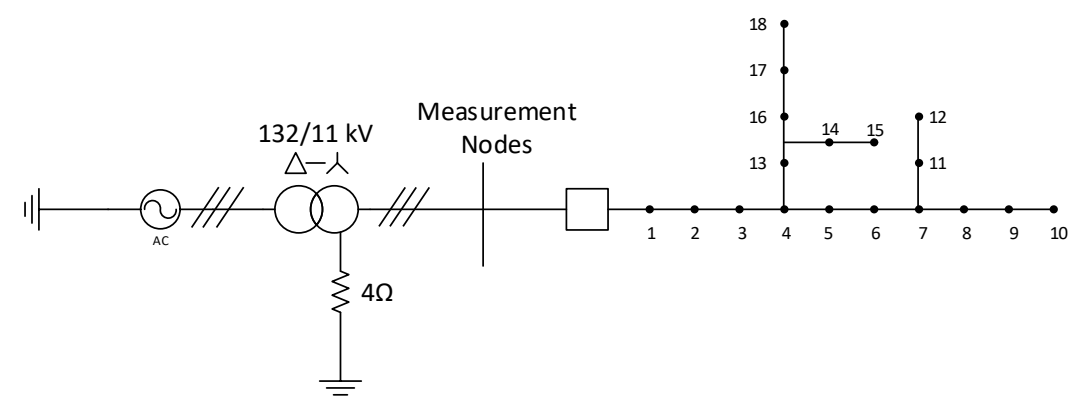

Figure 1. Simplified circuit configuration for a fault test

For this research, each of the nodes were simulated for different fault resistance value; $0.01 \Omega, 10 \Omega$, $30 \Omega, 50 \Omega$, and $70 \Omega$. The tested data of the voltage and current from the simulation were recorded in an excel file. These recorded data will be used in the Fuzzy Logic Toolbox as the inputs data for the fault type classification simulation.

Voltage \& Current Magnitude Pattern Recognization by Using Fuzzy Logic Toolbox for... (Lilik J. Awalin1) 


\section{FUZZY LOGIC DESIGN}

The block diagram was illustrated in Figure 2. is the general process for fault type classification. From the block diagram, the input data will be sent to Fuzzy Logic as voltage and current values. For these inputs, they will be the reference for Fuzzy Logic Toolbox rules design of each fault type. The Toolbox has the membership function for the rules setup and set the range data of the inputs. For this research, the membership functions will be set as the voltage and current for each phases during fault occurrence in the form of different states. This membership function act as the 'input filter' for which the rules condition was set up for the membership function to decide whether the input values satisfies the rules condition.

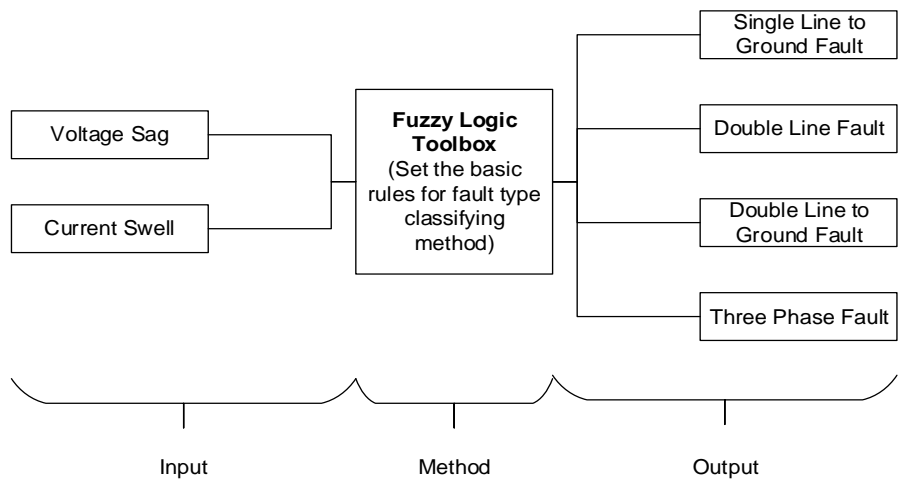

Figure 1. Fuzzy logic block diagram

\subsection{Membership Function}

Membership function in the toolbox categorizes the inputs according to its rules condition. Membership function was organized based on the range values of the inputs voltage and current that were analyzed for a certain measure. These range values were the pattern behavior of each fault type for a different fault resistance values. The observation through data analysis recorded the pattern behavior of each fault that satisfies the fault calculation theory. Figure 3 and Figure 4 shows the design of membership function for the input voltages and currents for each fault resistance.

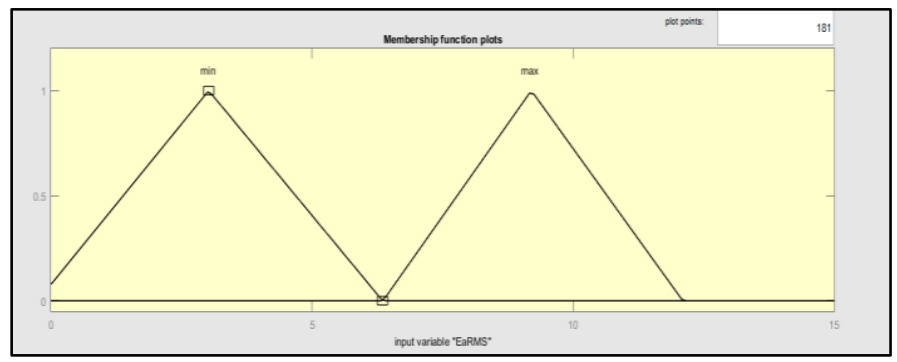

Figure 3. Membership function design of input voltages for each fault resistance

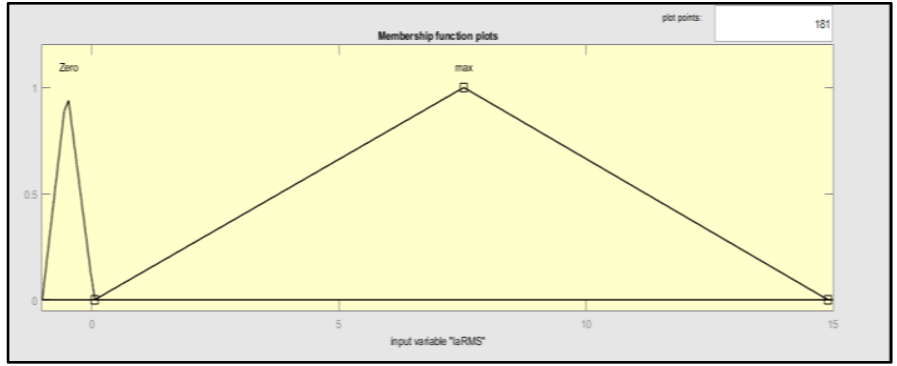

Figure 4. Membership function design of input currents for each fault resistance 
Additionally, Figure 5 shows the additional inputs that has been designed for $0.01 \Omega$ fault resistance only. Since both double line and double line to ground fault are having the similarity in pattern behavior, the additional inputs were designed in the membership function.

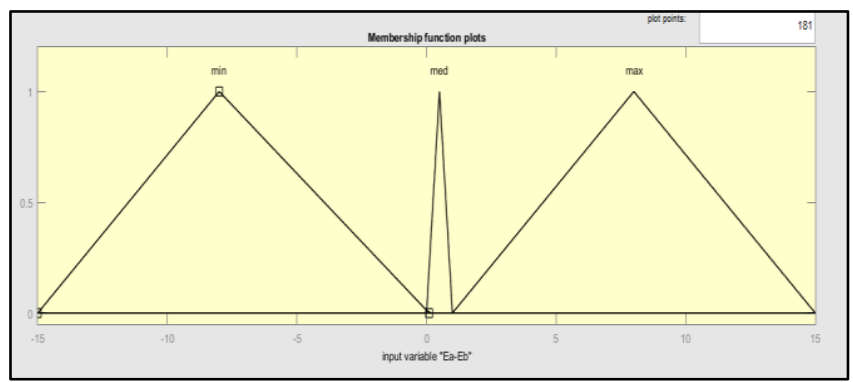

Figure 5. Membership function design of additional inputs for $0.01 \Omega$ fault resistance; ea-eb, eb-ec, \& ec-ea

\subsection{Rules Structure}

The toolbox was designed according to the rules structure. It is important in designing the toolbox because the simulation results are depending on the inputs and rules condition of the toolbox. The rules condition can only be decided with pattern behavior in determining the fault type. Each type of fault has their own rules condition that will decide their type. The numbers from 0-9 represents the output results of fault type classification.

Fault resistance $0.01 \Omega$ is considered as a low fault resistance. For a low fault resistance, the pattern behavior of voltage and currents are almost similar for each type of fault but with a bigger difference in terms of value number between each phases (phase $a, b \& c$ ). Hence, the rule structure for a low fault resistance was different from the other fault resistance. Table 1 shows the rules structure of a $0.01 \Omega$ fault resistance that has a similar pattern behavior between double line and double line to ground fault.

Table 1. Rules Structure for $0.01 \Omega$ Fault Resistance

\begin{tabular}{cccccccc}
\hline & \multicolumn{9}{c}{ Rules of the Module } & & \\
Ea & Voltage & \multicolumn{2}{c}{ Current } & Fault Type Classification \\
\hline Min & Max & Ec & Max & Max & Ib & Ic & \\
Max & Min & Max & Zero & Max & Zero & $\mathbf{0}$ & ZG \\
Max & Max & Min & Zero & Zero & Max & $\mathbf{2}$ & BG \\
\hline
\end{tabular}

\section{RESULT}

In conducting the Fuzzy Logic approach, this approach has shown its ability in detecting all type of faults. Overall, there are 18 nodes set as the reference point for each of the inputs in this research. The study foreseeing the relationship of different fault resistance, $R_{f}$ value and the fault distance towards the simulation results. Fault resistance is an error initiated at one point in a power system protection and fault location design during a fault occurrence that may cause disoperation in the system design and affect the current and voltage value. Meanwhile, the fault distance is the exact location where the fault takes place.

\subsection{Fault Resistance Effects in Classifying Fault Type}

The variety of fault resistance values shows different simulation results for which only $0.01 \Omega$ of fault resistance results are differ from the others. Results will cover the percentage of accuracy based on the 18 nodes data; whether or not the toolbox can detect the fault type for all the 18 nodes. An average calculation was used to find the average percentage of the fault type detected.

For a single line to ground fault, it consists of three different conditions that represents the connection of each phases and the ground; phase A to ground fault, phase B to ground fault and phase $\mathrm{C}$ to ground fault. 


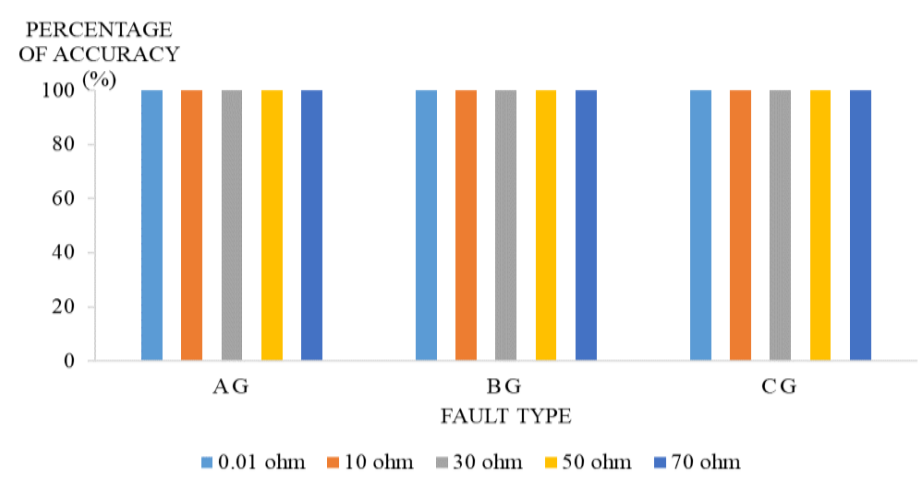

Figure 6. Percentage of accuracy in detecting single line to ground fault for each fault resistance

Figure 6 shows the accuracy of the toolbox in detecting the type of fault for the 18 nodes of each fault resistance. The bar chart shows that single line to ground fault has $100 \%$ of accuracy in fault type detection. The accuracy is depending on its input values which is meeting the rules requirement. Each type of single line to ground fault has been detected by using Fuzzy Logic method.

Table 5. Percentage of Accuracy for Fault Type Classification by Utilizing Fuzzy Logic Toolbox

\begin{tabular}{lcccccc}
\hline \multirow{2}{*}{$\begin{array}{l}\text { Fault } \\
\text { Type }\end{array}$} & \multirow{2}{*}{$\begin{array}{c}\text { Num. of } \\
\text { Node }\end{array}$} & $\mathrm{Rf}=$ & \multicolumn{5}{c}{ Percentage of Accuracy (\%) } \\
& & $0.01 \Omega$ & $10 \Omega$ & $30 \Omega$ & $50 \Omega$ & $70 \Omega$ \\
\hline AG & 18 & 100 & 100 & 100 & 100 & 100 \\
BG & 18 & 100 & 100 & 100 & 100 & 100 \\
CG & 18 & 100 & 100 & 100 & 100 & 100 \\
AB & 18 & 100 & 100 & 100 & 100 & 100 \\
\multicolumn{1}{c}{ AVERAGE } & $100 \%$ & $100 \%$ & $100 \%$ & $100 \%$ & $100 \%$ \\
\hline
\end{tabular}

Table 5 shows the percentage of accuracy for the toolbox in classifying each type of fault in total for different case of studies. High fault resistance shows the highest percentage with $100 \%$ compared to a lower fault resistance that has $100 \%$ accuracy in total.

\subsection{Fault Distance Effects in Fault Type Classifying's Accuracy}

The study proves that the toolbox can detect all type of fault with $100 \%$ of accuracy. Although the Toolbox was simulated with multiples inputs from different fault resistance, it can detect the fault type without any confusion. This study came across to see the effect of fault distance on the simulation results and the relation of it with fault resistance. Figure 6 shows the graph of different type of fault for a $0.01 \Omega$ fault resistance of the 18 nodes. For reference, an O-sign means the fault type of that particular fault location (nodes) is classified accurately and vice versa for a X-sign that represent the incorrect fault type was classified for that particular fault location.

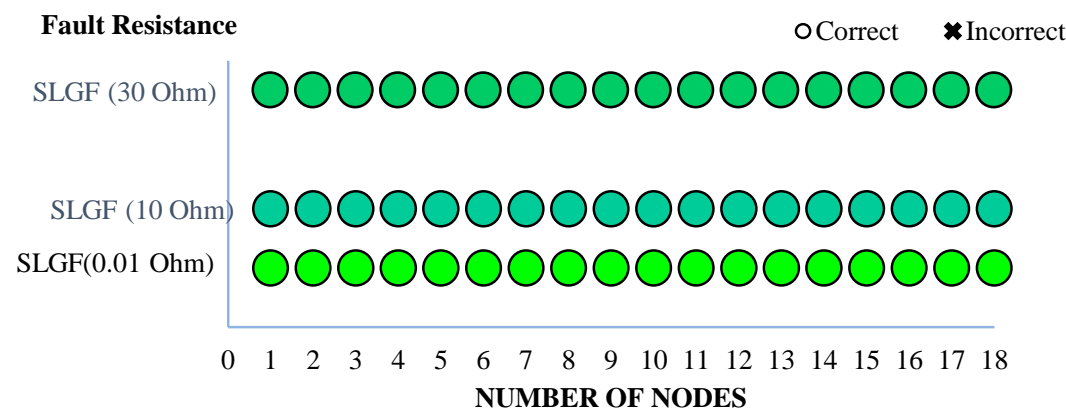

Figure 7. Fault distance impact on accuracy of fault type classification for $0.01 \Omega, 10 \Omega, 30 \Omega$ fault resistance 


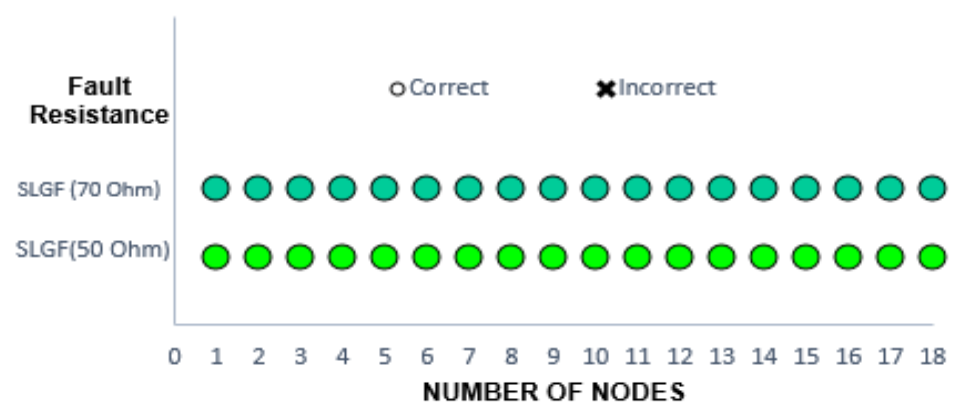

Figure 8. Fault Distance Impact on Accuracy of Fault Type Classification for a $50 \Omega$ and $70 \Omega$ Fault Resistance

From the shown graph in Figure 7 to 8, the distance or fault location does not affect the ability of Fuzzy Logic in determining the type of fault.From both figures shows that the ability of toolbox in classifying the fault type for a $10 \Omega, 30 \Omega, 50 \Omega$ and $70 \Omega$ fault resistance does not depends on the fault location. This means that Fuzzy Logic can still detect the type of fault with a 100\% accuracy though the fault location is still unidentified. As well as a higher fault resistance will not affect the percentage of accuracy in fault type detection, the 18 different fault location shows no effect on the simulation results.

Based on the observation, the fault distance does not affect the simulation results entirely. The error from which shown for a fault resistance $0.01 \Omega$ only due to the effect of fault resistance in fault type detection. For the research, there is no relation between fault resistance and fault location and it does shows that a fault location is not as crucial as fault resistance effect in determining the fault type.

\section{CONCLUSION}

This research proposed Fuzzy Logic method that able to determine the type of faults based on the input values of voltage sag and current swell. The output results of the simulation give an outstanding result where all of the fault type can be detected by using the proposed method. In addition, the research objective to test the ability of Fuzzy Logic to gives accurate results and to see which type of fault has the highest accuracy in Fuzzy Logic detection was a success. The average accuracy for the simulated results achieved $100 \%$ accuracy in fault type classifying.

Focusing on Fuzzy Logic as the only method in identifying and classifying the type of fault would have limited the scope of the research. So, for future study, the research can actually be expanded by using many methods which has been suggested such as wavelet transform, or combining Fuzzy Logic with other method such as wavelet transform and Artificial Neural Network (ANN). The combination of Fuzzy Logic and other proposed method might improve the accuracy and simplicity of the research.

\section{ACKNOWLEDGEMENTS}

The authors thanks to Universiti Kuala Lumpur, British Malaysian Institute for supporting this work through research grant of STRG (UniKL/CoRI/strl7073).

\section{REFERENCES}

[1] World Energy Needs and Nuclear Power. (2017, September). Retrieved November 14,2017, from http://www.worldnuclear.org/information-library/current-and-future-generation/world-energy-needs-and-nuclear-power.aspx

[2] Alsafasfeh, Q. H., Abdel-Qader, I., \& Harb, A. M. (2012). Fault Classification and Localization in Power Systems Using Fault Signatures and Principal Components Analysis. Energy and Power Engineering, 04(06), 506-522. doi:10.4236/epe.2012.46064.

[3] Heydar-Abadi, M. M., \& Foroud, A. A. (2013). Accurate Fault Classification of Transmission Line Using Wavelet Transform and Probabilistic Neural Network. Iranian Journal of Electrical \& Electronic Engineering, 9(3). Retrieved November 1, 2017.

[4] Saadat, H. (2010). Power system analysis (3rd ed.).

[5] Grigsby, L. L. (2012). The Electric Power Engineering Handbook, Third Edition - Five Volume Set. CRC Press.

[6] Bingham, R. P. (1998). Sags and swells. Manager of Technology and Products Dranetz-BMI 1994, Original Draft September 1994 Revised February 16, 1998, New Durham Road Edison, NJ 08818-4019 USA. 
[7] Filomena, A. D., Salim, R. H., M. R., \& Bretas, S. (2007). Fault Resistance Influence on Faulted Power Systems with Distributed Generation. International Conference on Power Systems Transients. Retrieved March 20, 2018.

[8] Pal, R., \& Gupta, S. (2016, December). Simulation of dynamic voltage restorer (DVR) to mitigate voltage sag during three-phase fault. In Electrical Power and Energy Systems (ICEPES), International Conference on (pp. 105110). IEEE.

[9] Jamil, M., Sharma, S. K., \& Singh, R. (2015). Fault detection and classification in electrical power transmission system using artificial neural network. SpringerPlus, 4(1). doi:10.1186/s40064-015-1080-x

[10] Jamil, M., Singh, R., \& Sharma, S. K. (2015). Fault identification in electrical power distribution system using combined discrete wavelet transform and fuzzy logic. Journal of Electrical Systems and Information Technology, 2(2), 257-267. doi:10.1016/j.jesit.2015.03.015.

[11] Patel, M., \& Patel, R. N. (2012). Fault Detection and Classification on a Transmission Line using Wavelet Multi Resolution Analysis and Neural Network. International Journal of Computer Applications, 47(22), 27-33. doi:10.5120/7489-0543.

[12] Prasad, A., Edwar, J. B., Roy, C. S., Divyansh, G., \& Kumar, A. (2015). Classification of Faults in Power Transmission Lines using Fuzzy-Logic Technique. Indian Journal of Science and Technology, 8(30). doi:10.17485/ijst/2015/v8i1/77065.

[13]Thwe, E. P., \& Oo, M. M. (2016). Fault Detection and Classification for Transmission Line Protection System Using Artificial Neural Network. Journal of Electrical and Electronic Engineering, 4(5), 89. doi:10.11648/j.jeee.20160405.11.

[14]Yadav, A., \& Dash, Y. (2014). An Overview of Transmission Line Protection by Artificial Neural Network: Fault Detection, Fault Classification, Fault Location, and Fault Direction Discrimination. Advances in Artificial Neural Systems, 2014, 1-20. doi:10.1155/2014/230382.

[15] MathWorks, Inc, and Wei-cheng Wang. Fuzzy Logic Toolbox: for Use with MATLAB: User's Guide. Mathworks, Incorporated, 1998.

[16] Hessine, M. B., Marrouchi, S., \& Chebbi, S. (2017, January). A fault classification scheme with high robustness for transmission lines using fuzzy-logic system. In Advanced Systems and Electric Technologies (IC_ASET), 2017 International Conference on (pp. 256-261). IEEE. 